\title{
LA RAZÓN EVALUADORA EN PAUL RICOEUR. TRAZOS PARA UN DESARME DE LA MÁQUINA QUE AJUSTICIA
}

\author{
Facundo Giuliano ${ }^{1}$
}

\begin{abstract}
Resumen:
No ha sido menor la influencia de Paul Ricoeur en el ámbito de la filosofía en general y de la filosofía de la educación la educación en particular, al punto que muchas veces ha sido repetido sin atender algunas consecuencias de sus posiciones ético-políticas que fortalecen directamente la sinonimia entre educación y evaluación. Este ensayo busca explorar y confrontar dichas posiciones al mismo tiempo que intenta contrarrestar la racionalidad evaluadora que subyace en ellas y conforma esa suerte de "máquina que ajusticia". Para ello, se exploran algunas de las principales obras e intervenciones teóricas del autor a modo de visualizar la progresión de su argumentación y discutirlas con cierto detalle. Por último, se plantea un desenlace reflexivo que atiende a la potencia de habitar subversivamente los contornos desde los cuales puede jugarse de otro modo la educación contemporánea.
\end{abstract}

Palabras claves: Filosofía de la educación. Ética. Pedagogía. Razón evaluadora. Política.

\section{EVALUATIVE REASON IN PAUL RICOEUR: NOTES FOR THE DISARMING OF THE EXECUTING MACHINE}

\begin{abstract}
:
The influence of Paul Ricoeur in the field of philosophy in general and the philosophy of education in particular has not been minor, to the point that it has often been repeated without addressing some consequences of his ethical-political positions that directly strengthen the synonym between education and evaluation. This essay seeks to explore and confront these positions while trying to counteract the rationality that underlies them and forms that sort of "machine that executes." To do this, some of the author's main theoretical works and interventions are explored in order to visualize the progression of his argument and discuss them in some detail. Finally, there is a reflexive outcome that addresses the power of subversively inhabiting the contours from which contemporary education can be played otherwise.
\end{abstract}

Keywords: Philosophy of education. Ethics. Pedagogy. Evaluative reason. Politics.

1 Doctor por la Facultad de Filosofía y Letras de la Universidad de Buenos Aires. Director del proyecto de investigación FiloCyT "Educación, filosofía y psicoanálisis: la potencia de um anudamiento indisciplinario frente al capitalismo contemporáneo" con sede en el Instituto de Investigaciones en Ciencias de la Educación (UBA). Pertenece al Consejo Nacional de Investigaciones Científicas y Técnicas (CONICET, Argentina). Ha sido profesor/investigador visitante de la Universidad Complutense de Madrid y de la Universidad de Barcelona, donde también ha dictado clases y conferencias. Ha dictado seminarios de grado y posgrado, y publicado en revistas del ámbito nacional e internacional sobre cuestiones que vinculan problemáticas propias de la educación, la filosofía, la literatura, el psicoanálisis y la política. Autor de "Rebeliones éticas, palabras comunes. Conversaciones (filosóficas, políticas, educativas) con Judith Butler, Raúl Fornet-Betancourt, Walter Mignolo, Jacques Rancière, Slavoj Žižek” (Miño y Dávila, 2017) y de “¿Podemos pensar los no-europeos? Ética decolonial y geopolíticas del conocer" (del Signo, 2018). 


\section{Comunión de libertades y razón evaluadora: ego-logias, reglas y sedimentación.}

En la década de 1980, Paul Ricoeur ofreció una serie de conferencias en la Universidad de Buenos Aires, una de las cuales tocó una cuestión que de diferentes modos tendería a abordar en sus obras posteriores: la evaluación. Allí plantea que el verbo (evaluar) habita primeramente la palabra 'valor' y remite siempre a una preferencia ('esto' vale más que ‘aquello', lo cual pre-supone una escala de superioridad/inferioridad). La preferencia sería así "el atributo de un ser de voluntad y de libertad" y solo quien puede ponerse en una posición autoral sobre sus actos, como "agente moral", puede "jerarquizar sus preferencias" (Ricoeur, 2011, p. 75). Esta posición de "libertad" en primera persona, agente y soberana, para Ricoeur (2011) es esencial a la evaluación e implica poner en juego el juicio moral que se torna inseparable de un círculo vicioso en el que la efectuación de esa libertad (inscripta en actos y obras) al tiempo que ejerce un juicio requiere la potencialidad de ser juzgada por otros (así como el juicio requiere de más juicio, la evaluación demanda más evaluación y, como esta es heredera genealógica de aquel, su funcionamiento parece mostrar en ello una línea de continuidad). Siguiendo el planteo, esta referencia a la evaluación por (y de) otro elevaría lo valioso por encima de "lo simplemente deseable" en función de la "ayuda" entre libertades que no se da sin el requerimiento ${ }^{2}$ de una para con otra.

Además de la idea de un sujeto individual, soberano, ego-lógico y dueño absoluto de sus actos, que no se narra para nada condicionado (ni desposeído) por el contexto y tampoco por el inconsciente que forma parte de él, aparece el problema del reconocimiento del otro aunado al factor subjetivo de evaluación, es decir, "al poder subjetivo e íntimo de preferir una cosa a otra" (Ricoeur, 2009, pp. 75-76). El mismo texto da la pauta de cómo trabaja la evaluación sobre sujetos singulares reducidos a meras cosas que podrán ser preferidas o no cual mercado de preferencias, y como toda preferencia, condicionadas siempre por relaciones de poder que producen subjetividad en el marco del capitalismo y su colonialidad. Dicho problema entre reconocimiento y evaluación es resuelto por Ricoeur (2009) apelando a una regla previa que sería una "mediación tercera", caracterizada por su "neutralidad", y que otorgaría al valor (inscripto en una historia cultural de las costumbres) una suerte de objetividad capaz de presentarlo como patrón de medida. Esta exigencia se satisface cuando el valor actúa entonces como "marca de excelencia de las acciones" (Ricoeur, 2009, p. 76).

2 Esta es otra manera de visualizar cómo el Requerimiento no solo es una escena fundante de la educación colonial, sino un síntoma que se repite (Giuliano, 2017) de diversos modos hasta nuestros días.

\begin{tabular}{|c|c|c|c|c|}
\hline Rovista Dialectus & Ano 9 & n. 19 & Agosto - Dezembro 2020 & p. $25-37$ \\
\hline
\end{tabular}


Se descuida así el tránsito por demás peligroso hacia la normación, la normalización o la reducción de cualquier diferencia a lo mismo y se traza el reconocimiento como el encuentro entre dos "sujetos ego-lógicos que hacen uso de algún poder soberano para evaluar(se)" (Giuliano, 2016, p. 13). Por lo tanto, con las situaciones ya calificadas -o codificadasmoralmente de antemano, la educación se reduce (en complicidad sinonímica con la evaluación) a inscribir el proyecto de cada quien en esa "historia cultural de los valores" que, como "sedimentos depositados por las preferencias individuales y los reconocimientos mutuos", sirven de "relevos objetivos entre nuevos procesos de evaluación de los que cada individuo es responsable" (Ricoeur, 2009, p. 77).

Una cosa lleva a otra, pero todos los caminos conducen a la evaluación en esa historia que, para Ricoeur (2009), también debería inscribirse en los proyectos singulares y, por supuesto, jalonar sus trayectos de efectuación. En cierta forma, se trataría de una interiorización que anula cualquier afecto de alteridad en función de una sedimentación que estabiliza (normaliza) preferencias, apreciaciones, estimaciones, de modo que, siguiendo a Ricoeur (1996), la persona se reconoce en sus disposiciones evaluativas. ${ }^{3}$ Esto último, como atinadamente señala Ricoeur (1996), se relaciona con la teoría freudiana del superyó que da a la interiorización un aspecto de sedimentación: punto de encuentro entre los valores (arriba mencionados como 'sedimentos') y el tribunal psíquico del cual "el sujeto escindido en 'instancias' distintas, actuando unas contra otras" ocupa a la vez los lugares de acusado y acusador, juez y víctima (Balibar, 2014, p. 231). Por ello también la lucha contra la evaluación, el juicio y sus instancias, es también interna y singular.

\section{El circu(l)ito vicioso de la razón evaluadora: deseo de juicio, patrones de excelencia y solipsismo.}

Unos años después, Ricoeur (1996) brindará una nueva coordenada que permite ver cómo funciona el circu(l)ito vicioso de la evaluación. Pues si antes vimos que la evaluación se trataba de que 'lo valioso' se ubique por encima de 'lo simplemente deseable', ahora veremos que, incluso en la formación del deseo, ya puede haber un componente evaluador y, por ende, un papel del juicio. Esto se configuraría así precisamente porque, según Ricoeur (1996), formar un deseo o una intención equivale a "llegar a un juicio" (p. 68). Tal vez habría que pensar en

Aquí también se podría subrayar una relación circular entre el “dispositivo de la persona” y las disposiciones evaluadoras en las que se reconoce, como puede notarse mejor en Giuliano (2019).

\begin{tabular}{|c|c|c|c|c|}
\hline Romita Didectus & Ano 9 & n. 19 & Agosto - Dezembro 2020 & p. $25-37$ \\
\hline
\end{tabular}


qué tipo de deseo o intención se forma con esa base pragmática judicial ya que, por ejemplo, el deseo que sostiene una exploración literaria se alimenta del placer que implica una suspensión del juicio y una instalación en la experiencia del conflicto o la incertidumbre. Como retomaremos en detalle más adelante, para Ricoeur (1999), la finalidad inmediata del acto de juzgar es zanjar un conflicto, poner fin a la incertidumbre, en otras palabras, una lógica que parece no entender los juegos del deseo y de, por continuar con el ejemplo, la literatura.

El juicio caracterizado por la idea consensual y pospolítica del conflicto como par opuesto a la paz social es tan afín a Ricoeur (1999) como la sinonimia entre ética y moral (de la que también es tributaria la de educación y evaluación), ambas compatibles con la finalidad planteada a largo plazo de la "sociedad como empresa de cooperación, al amparo de pruebas de aceptabilidad que exceden el recinto de los tribunales y ponen en juego el auditorio universal" (p. 22) -énfasis nuestro-. Una empresa que se parece a una máquina deslocalizada e incesante de juicio que hasta en el recinto de la ficción se jacta de "explorar nuevos modos de evaluar" mediante "variaciones imaginativas" que airean su contenido lógico y moral. De este modo se busca, entre otras cosas, consolidar la idea de que sin la evaluación nada tendría sentido y que gracias a ella "el relato puede finalmente ejercer su función de descubrimiento y también de transformación respecto al sentir y al obrar del lector" (Ricoeur, 1996, p. 167). Plantear así en la relación a la lectura (de un texto y del mundo) una dependencia con la evaluación, parece una importante estrategia para implantar la razón evaluadora al nivel del sentir (aiesthesis) y el hacer (praxis) de modo tal que dicha dependencia se instala también para toda la existencia. Llegados a este punto de la evaluación atravesando todo a su paso, Ricoeur (1996) propone el término "Transvaluar" y vemos ya que hasta la imaginación y la fantasía no se salvan de "revivir modos de evaluar que continúan perteneciendo a nuestra humanidad profunda" (p. 167). Pero, ¿de qué humanidad hablará el autor? ¿Será acaso de la misma en nombre de la cual se negó la humanidad de otros? ¿Será acaso aquella que sub-clasificó a las demás para ella entronizarse como primera importancia del mundo? Aquí es donde puede recordarse algo ya planteado y que hasta el mismo autor sostiene: como "devaluar es también evaluar", no puede descuidarse que ahí actúa una dependencia ontológica y que, como una no funciona sin la otra, hay que prestar atención qué se devalúa cuando se evalúa. Y aquí hay un elemento clave de la razón evaluadora, sin el cual no procede en sus fines: la comparación.

Anteriormente vimos que la regla aparecía como esa terceridad pretendidamente neutra que objetiva el valor como patrón de medida y media las relaciones entre reconocimiento y evaluación. En una nueva vuelta al asunto, Ricoeur (1996) le otorga una dimensión

\begin{tabular}{|l|l|l|l|l|}
\hline Govista Dialectus & Ano 9 & n. 19 & Agosto-Dezembro 2020 & p. 25-37 \\
\hline
\end{tabular}


constitutiva que abriría "el espacio de sentido en el que pueden desplegarse apreciaciones de carácter evaluador (y posteriormente, normativo) vinculadas a los preceptos del bien hacer” (p. 181). Curiosamente, la calificación "ética" de dichos preceptos estaría garantizada para Ricoeur (1996) por lo que MacIntyre llama "patrones de excelencia” y que, básicamente, son "reglas de comparación aplicadas a resultados diferentes, en función de los ideales de perfección comunes a cierta colectividad de ejecutantes e interiorizados por los maestros y los virtuosos de la práctica considerada" (p. 181). Este recurso es planteado como "precioso" para refutar “cualquier interpretación solipsista de la estima de sî”, pero en realidad puede notarse que no hace más que codificar o reglamentar la imposición de una interpretación hegemónica sobre lo considerado estimable o excelente en desmedro de todo aquello que puede serlo y no comparte los "ideales de perfección" dominantes ni mucho menos ha sido interiorizado hegemónicamente por quienes son calificados como portadores de cierto virtuosismo.

Ahora bien, cuando Ricoeur (1996) se pregunta qué es lo que declara al sí “digno de estima" plantea que hay que responder que no sus realizaciones, sino fundamentalmente sus capacidades. El término capacidad, tan de moda en la pedagogía neoliberal que lo utilizó de reemplazo del término competencia, Ricoeur (1996) lo remonta al "yo puedo" de MerleauPonty y lo inscribe en el plano de la autoevaluación: el Yo sería ese otro que puede evaluar sus acciones (y estimando buenos los fines de ellas, estimarse bueno a sí mismo), que despliega la capacidad de evaluarse a sí mismo (¿de bastarse a sí mismo?). Sin salir en defensa de la heteroevaluación (o la evaluación por otro), no deja de llamar la atención el giro solipsista y autosuficiente que entraña el argumento, pues ¿no se trataría también de una interpretación solipsista de la estima de sí en la que las "reglas de comparación”, en lugar de refutarla, terminan consolidándola? No pareciera haber mucho lugar para el otro en un espacio en que el Yo todo lo ocupa y todo lo puede al punto que incluso puede ser ese otro u ocupar su lugar, por lo que el Sí mismo como otro termina por confirmarse aquí como una impostura que aporta un maquillaje políticamente correcto a una prescindencia de la alteridad y que acentúa el poderhacer como poder-juzgar. Lejos queda el "Yo es otro" de Rimbaud, para des-cubrirse que Yo es un sí mismo que simula estar con y para el otro o, directamente, se viste con sus ropajes y lo despoja con tal de ser como él.

También el otro puede servir (o ser usado) pragmáticamente como el soporte que brinda aprobación o crédito a la "propia capacidad", lo que constituye una manera de sostener el poder-hacer en la razón evaluadora. De modo que, como luego reafirmará Ricoeur (2006), es en la base de esa idea de poder-hacer donde opera la evaluación de capacidades unida, de

\begin{tabular}{|l|l|l|l|l|}
\hline Qenista Dialectus & Ano 9 & n. 19 & Agosto-Dezembro 2020 & p. 25-37 \\
\hline
\end{tabular}


modo secreto, a la idea de "vivir bien", al mismo tiempo que tales capacidades se promueven a criterio de evaluación. Criterios que introducen una "economía de la grandeza" y opera calificando a las personas en función de una situación que las posiciona en una escala a partir de cierto tipo de éxito social, lo cual establece una disputa por las pruebas de calificación que, para Ricoeur (2006), concuerda con su concepto de "lucha por el reconocimiento" (p. 260). Como si la evaluación de capacidades permitiera "vivir bien" y se perdiera de vista el costo que supone cosificarse u objetualizarse en el afán de entrar en la tierra prometida del éxito o "la grandeza”, así como la disputa constante por “calificar” en el círculo vicioso de la evaluación que siempre demanda más evaluación. En este marco, Ricoeur (2006) plantea el reconocimiento asociando ‘distinción' e ‘identificación' y constituyéndolo en “un binomio verbal indisociable" en tanto distinguir sería identificar y viceversa, lo cual le lleva a sostener que "la persona humillada aspira precisamente a ser distinguida e identificada” (p. 41). Resulta algo extraño que además del flagelo que supone la humillación en cualquiera de sus formas, quien la padece pretenda someterse también a evaluación ya que esta supone simepre las "dos operaciones establecidas en repertorio en la raíz misma del acto de juzgar: distinguir e identificar" (Ricoeur, 2006, p. 40). Y esto nos habilita, ahora sí, a explorar la noción subyacente de acto de juzgar que, como hemos visto, sigue inscribiéndose o pervive de hecho en la razón evaluadora.

\section{Sobre el acto de juzgar: elementos y repartos.}

Hacia mediados de la década de 1990, Ricoeur (1999) dedica una conferencia al acto de juzgar donde traza una especie de fenomenología y lo ubica al final de una deliberación (a pesar de que todo juicio siempre invoca un "más allá de él mismo", cierta estructura de infinitud). En este marco, prolonga el sentido no técnico del acto de juzgar, es decir, de estipular en calidad de juez y establece una cadena semántica que va de la opinión a la estimación e introduce un elemento jerárquico y jerarquizante que expresa preferencia, apreciación, aprobación. Se dibuja así en el juicio un punto de encuentro entre un aspecto pretendidamente objetivo y uno subjetivo, como también -en sintonía con Descartes- la conjunción del entendimiento (que considera lo verdadero y lo falso) y de la voluntad (que decide). De aquí que para Ricoeur (1999) juzgar sea “en última instancia adoptar una posición” (p. 177) al nivel de una sanción que interviene en (tanto como coloniza) la práctica social y siempre implica ganadores y perdedores en un proceso aleatorio del que se conocen las reglas, pero se ignoran los finales. No obstante, el acto atribuye a cada uno "lo suyo", es decir, re-parte (establece las

\begin{tabular}{|l|l|l|l|l|}
\hline Govista Dialectus & Ano 9 & n. 19 & Agosto-Dezembro 2020 & p. 25-37 \\
\hline
\end{tabular}


partes), separa o, para decirlo con Rancière, produce un reparto o una división que define ocupaciones específicas y dota de capacidades (y sensibilidades) según las mismas. En el fondo de este planteo reposa la filosofía de Kant que tan interesado estaba en la distinción entre "lo mío" y lo "lo tuyo", en "el acto que establece una línea entre lo uno y lo otro" (Ricoeur, 1999, p. 180), que para Deodoro Roca (2008) murió de su “imperativo”, de su dogmático “debe ser”, fundido con ayuda del "aire confinado de un 'yo', hinchado como un fuelle” (p. 216) -así se entiende mejor el importante énfasis en el Yo que encontramos en Ricoeur-.

Siguiendo a Ricoeur (1999), el acto de juzgar llega a su meta cuando quien gana reconoce en quien pierde que sigue siendo como sí mismo, pero el reconocimiento se torna “completo" solo si quien pierde (quien no tuvo razón, quien será condenado/a) reconoce lo mismo en quien gana y llega a "declarar que la sentencia que le quita la razón no es un acto de violencia, sino de reconocimiento" (p. 181). Así la sanción también alcanzaría su objetivo al ser aceptada o comprendida por quien la sufre, aunque se descuida que "la ejecución de la pena equivale a un proceso de desocialización acelerada" (Ricoeur, 1999, p. 193), un proceso de exclusión que lejos está de re-insertar, restablecer o restaurar algún orden. Sin embargo, el planteo de Ricoeur aspira a que quien padece la sanción la elabore como un reconocimiento de ser razonable, responsable, "dueño" o autor de sus actos, paradoja que Hegel extremaba cuando sostenía que la pena de muerte era una forma de "honrar al culpable en tanto que ser racional" (citado en Ricoeur, 1999, p. 190). Exploramos de este modo, otro vínculo de la razón evaluadora y la razón punitiva (Giuliano, 2020), al que podría sumarse esa transformación del sujeto de carne y hueso en mera "parte" del proceso (otro nombre para la objetualización o cierta cosificación).

\section{La fuerza de la razón evaluadora en la existencia: precepto socrático, discriminación y jerarquización.}

Ricoeur (1999) toma la noción de "evaluaciones fuertes" del libro Fuentes del yo de Charles Taylor que aborda la construcción de la identidad moderna, y las entiende en primera instancia como las estimaciones más estables de la conciencia común que, por su estructura binaria, expresan cada una a su manera la discriminación entre el bien y el mal. Siguiendo la sugerencia de Taylor, deduce de la correlación entre el sí mismo y la idea del bien la expresión que presidiría toda búsqueda de identidad personal y que "encuentra un esbozo de respuesta en las modalidades de adhesión por las cuales respondemos a la solicitación de las evaluaciones

\begin{tabular}{|l|l|l|l|l|}
\hline Gonista Oialeatus & Ano 9 & n. 19 & Agosto-Dezembro 2020 & p. 25-37 \\
\hline
\end{tabular}


fuertes" (Ricoeur, 1999, p. 199) -énfasis nuestro-. Esto supone ubicar la evaluación al nivel de la existencia y la identidad (probablemente sea en el terreno de identidad, así como en el de la identificación, donde mejor se mueva), aunque también el hecho de que se señalen "modalidades de adhesión" deje abierta la puerta a diferentes formas de rechazo a la solicitación evaluadora.

No obstante, la relación existencia-evaluación se plantea también cuando Ricoeur (1999) sugiere que el término evaluación "expresa el hecho de que la vida humana no es moralmente neutra" sino que, "desde que ella está sometida a examen, según el precepto de Sócrates, se dispone a una discriminación de base entre lo que es aprobado como mejor y lo que es desaprobado como peor" (p. 198) -énfasis nuestro-.$^{4}$ O, como dirá Ricoeur (2008) tiempo después, se llega así a "un nivel existencial de la evaluación" en el que "la norma no es definida ya estadísticamente como media, sino como proyecto singular, lo que Sartre llamaba proyecto existencial" a partir del cual el individuo "se define por referencia a él mismo, en función de su horizonte de transformaciones con sus criterios personales de realización y de evaluación" (p. 180). De este modo resuelve también lo que considera "una operación extremadamente compleja" (Ricoeur, 1999, p. 204) por involucrar procesos "enmarañados" de interpretación y que refiere al hecho de aplicar una norma a un caso particular.

De aquel planteo podría inferirse que, tal vez, la potencia de cierta ética radique en la neutralización de la moral como forma de dejar de someter la vida a la razón evaluadora, es decir, como forma de suspender o sustraer la discriminación, como forma de dejar de aprobar aquello que se construye como "mejor" y tantas veces resulta perjudicial, o dejar de desaprobar eso que se percibe como "peor" y podría salvarnos la vida... Pero si la vida se torna evaluadora, si nos instalamos en ese nivel existencial normativista o normalizador en el que incluso fabricamos nuestra propia norma, nos convertimos en empresarios de nosotros mismos y caemos en la depuración de la alteridad que nos lleva a definirnos por referencia a nuestros criterios personales, ¿qué es lo que resta? ¿qué es lo que difiere? ¿a dónde quedan los demás entre tanto solipsismo? ¿No se trata acaso de una modalidad de vida o un "proyecto existencial" rotundamente individualista y fuertemente funcional al capitalismo en su fase neoliberal? La genealogía juicio-examen-evaluación se tornaría ya insoslayable para la existencia, y vemos

\footnotetext{
4 Un ejemplo de cómo algunos planteos filosóficos de la educación pueden encontrarse influidos por Ricoeur, puede leerse en la discusión que se plantea en Giuliano (2018) y ubica la aprobación/desaprobación como dos caras de la razón evaluadora.

\begin{tabular}{|c|c|c|c|c|}
\hline Ropista Dialectus & Ano 9 & n. 19 & Agosto - Dezembro 2020 & p. $25-37$ \\
\hline
\end{tabular}
}


que la evaluación no se deshace del examen, así como antes vimos que no se olvida del acto de juzgar, ambos perviven en ella de formas variables.

En un segundo momento, Ricoeur (2008) retoma la noción de "evaluaciones fuertes" para referir a cuando las significaciones "recaen sobre el curso entero del proceso histórico de racionalización del mundo", ya se trate del mundo económico del trabajo, de la riqueza y de la diversión, pero también para referirse al registro de lo político "bajo la figura de los grandes motivos de obediencia, que contribuyen a la legitimación de la dominación” (p. 141). Esta vuelta de tuerca no sorprende en tanto consideramos que la racionalidad propia de la evaluación tiene de por sí sus (inter)relaciones con el mundo del trabajo (que incluye la producción de riqueza e incluso el ocio o la diversión como forma de producir ganancia) y la legitimación de la dominación en tanto imposición de obediencia a sus propias lógicas. Si en el primer abordaje de la noción se hacía hincapié en la estabilidad de estimaciones binarias que habilitaban una discriminación, en este segundo abordaje ello se da por hecho y se pasa a brindarle una legitimidad socio-económica y política a las relaciones de obediencia y dominación que implica.

Lo señalado puede verse mejor cuando esta noción así referida es planteada por Ricoeur (2008) como una “dimensión ineluctable, inexcusable, indispensable” (p. 156) y desglosa sus componentes para precisar que 'evaluación' implica polarización (que pone una marca moral sobre deseos, inclinaciones y reacciones) y discriminación (a partir de binomios tales como bien/mal, mejor/peor, honorable/deshonroso, digno/indigno, admirable/abominable), mientras que el adjetivo 'fuerte' insiste sobre la "profundidad" (en relación con los cambios rápidos de deseos, reacciones y disposiciones -siempre más duraderas que las emociones-), el poder (en tanto capacidad de motivación) y la universalidad (su pretensión de ser "compartida", su búsqueda de aprobación en el otro) de la evaluación. Siguiendo a Ricoeur (2008), esto último incluiría a las convicciones que, en esa búsqueda de aprobación, también son ofrecidas y resta entonces la pregunta sobre qué sucede con ellas en caso de no ser aprobadas... ¿se cambian, se disfrazan, se simulan otras, se descartan y se adoptan las de quien evalúa? No es un punto menor frente a una razón de impostura que se presenta como "inevitable recurso" y que otorga significado moral a la vida, al mismo tiempo que busca reforzarse la tesis según la cual se presupone que "la idea de evaluación puede resistir a la erosión de toda la herencia cultural, tanto moderna como antigua” (Ricoeur, 2008, p. 157).

La segunda característica de las evaluaciones fuertes, la discriminación, le permite a Ricoeur (2008) poner sobre el tapete algunos componentes de lo que llama el "universal

\begin{tabular}{|l|l|l|l|l|}
\hline Govista Dialectus & Ano 9 & n. 19 & Agosto-Dezembro 2020 & p. 25-37 \\
\hline
\end{tabular}


concreto". Por ejemplo, (la implicación de) la jerarquización haría que el deseo de vivir bien penetre en las esferas de la obligación moral -con sus rasgos de "universalidad" e “imparcialidad"-. En este marco, la llamada socrática a una "vida examinada" juega una fuerte presión favorable a invocar una instancia extrínseca del juicio que pretende decir en razón de qué estimamos 'esto es mejor que aquello'. Ahora bien, si quisiera esbozarse algún tipo de crítica a cualquier instancia del proceso, para Ricoeur (2008) solo podría hacerse en sus propios términos:

es preciso decir que la crítica de los términos evaluadores no puede hacerse en otro lenguaje que no sea él mismo evaluador. La justificación es constitutiva de la fuerza de una evaluación, y las razones de rango superior permanecen homogéneas a las evaluaciones fuertes. (...) La distancia crítica es así un momento de la evaluación. Queda la consideración de este momento de discriminación que acentúa el carácter transhistórico o a-histórico de la noción misma de evaluación (p. 157).

Nuevamente, desde dicha posición, la crítica es un momento más de la razón evaluadora y la circularidad que impone criticarla solo en sus propios términos y lenguaje. Lo que no hace otra cosa que justificarla incesantemente e intentar quitarla de la historia para garantizar su continuidad, mantenerse a través del tiempo y del espacio. En este sentido, Ricoeur (2008) señala que las evaluaciones fuertes otorgan "orientación en un espacio moral (aspecto al cual se es particularmente sensible cuando uno se siente desorientado o, como se dice espontáneamente hoy, privado de referencias)" (p. 159), como una "carta de navegación" sobre la que se han dispuesto las referencias "éticas" que regularían la orientación sobre la cual se abren nuestros ángulos de perspectiva en la deriva, la partida y el retorno.

Así, tanto los tratados de virtudes de los antiguos como los clásicos expresan una pluralidad de referencias de evaluación que no escapa a la estructuración moral de la experiencia con su respectivo perfil jerárquico y su presentación como un marco inescapable e inevitable. De esta manera, se afirma estas estructuras como "insuperables” y "trans-históricas" a la vez que se les permite ser "discutidas" en el "punto de articulación entre lo universal formal y el juicio moral en situación" (Ricoeur, 2008, p. 169), es decir, fundamentalmente en su interior. Todo lo cual lleva a preguntar si en ese marco se puede atravesar alguna experiencia sin comenzar por evaluar, continuar por aprobarla o reprobarla, y finalizar con la idea de que todos los caminos conducen a la posición evaluante que permite -a Ricoeur (1990) y sus seguidores- rechazar y encerrarse en una impulsividad instantánea que segrega un "terrible proceso de sedimentación” (p. 302).

\section{Desenlace: nota por un desarme de la máquina que ajusticia.}

\begin{tabular}{|l|c|c|c|c|}
\hline Govista Dialectus & Ano 9 & n. 19 & Agosto-Dezembro 2020 & p. 25 - 37 \\
\hline
\end{tabular}


Ricoeur (2006) nos ha mostrado que, hasta la alabanza, en el lenguaje infecto de la razón evaluadora, sería una “"evaluación importante’ expresada a la manera del canto” (p. 281). Todo pareciera conducir a una gran máquina que todo lo asimila, lo puntúa, lo valúa. Se fabrica un culto del Yo, del sí mismo que no deja de ser un fantasma deslizándose por la agrietada máscara de las buenas intenciones y que intenta sujetarnos (y esclavizarnos) en el teatro de la crueldad donde monta sus fatídicas escenas. No hace falta estar a la caza del prójimo, para esperar el instante en que el rostro descuida el antifaz. En los intervalos opresores de la espera, no se puede vivir de exactas referencias o de comprobadas exactitudes. Se necesita con-fundir, errar con nobleza y anticiparse con osadía frente a la duda que inocula cualquier culpa individual. Como la fantasía, es una necesidad colectiva. Algo se juega en ello: encontrar un escondite, encontrar lo nunca enteramente perdido, imitar el encuentro trascendental del deseo con alguna verdad, perderse y encontrarse. Para Deodoro Roca (2008), estos serían los mejores juegos de infancia: los que hay que encontrar (escondites) por seguir jugando, entre la impaciencia de lo oculto y la alegría del hallazgo.

Quizá así pueda detenerse (y desarmarse) la máquina que ajusticia, la misma que con seguridad y supuesta precisión funciona a base de devorar mártires de la esperanza. Sobre esa máquina que tritura incontables vidas, Deodoro Roca (2012) dice que no hay palabra más exacta que la describa: “Ajusticia”, que quiere decir "“no justicia', cosa fuera de la justicia” (p. 438). Funciona admirablemente, aunque su resorte vital esté roto y la sociedad que la puso en marcha esté cada vez más desprotegida de la misma. Jueces y evaluadores de todos los tiempos y de todas las partes le aportan sus veredictos infamantes para convencer al mundo de que su Justicia es infalible, mientras inocentes caen sin suelo o son inyectados por el kilowatt del momento, hacen de su inflexibilidad la garantía suprema de la mismidad. De aquí que nos unamos al llamado de Roca (2012), que desde aquel 1927 convoca la unión obrera-estudiantil para defender a la otra justicia. Una justicia de alteridad, quizá.

Ahí tal vez el principal modo de terminar con la apetencia de la cantidad, "la autofagia que se incrementa en la proporción en que es satisfecha" (Roca, 2012, p. 122), reinado de la fuerza y alegría de unos pocos sobre el dolor de los demás. No basta con sentir en lo íntimo del alma la tragedia de un mundo que se desgarra, se necesita de la trinchera con cuidado sentido de las realidades históricas y con agudo entendimiento del drama social y político pedagógico que nos toca. Y desde ahí dar una lucha que se teje entre señales, a veces alteradas, que buscan llamar la atención sobre problemas candentes como el aquí asomado: combatir la razón

\begin{tabular}{|l|l|l|l|l|}
\hline Qenista Dialectus & Ano 9 & n. 19 & Agosto-Dezembro 2020 & p. 25-37 \\
\hline
\end{tabular}


evaluadora en todas sus formas, incluso en las más elegantes y decorosas. Porque hay docentes que lo hacen cada mañana, tarde y noche, no se entregan del todo al sistema que dicha racionalidad les propone, no se resignan al silencio cómplice ni se entregan a las vocinglerías gárrulas, hacen de su lugar una poética y de su pensar una enseñanza.

\section{Referencias bibliográficas:}

Balibar, É. Ciudadano sujeto: ensayos de antropología filosófica. vol. 2. Buenos Aires: Prometeo, 2014.

Giuliano, F. La educación, entre la mismidad y la alteridad: Un breve relato, dos reflexiones cuidadosas y tres gestos mínimos para repensar nuestras relaciones pedagógicas. In: Voces y silencios. Revista Latinoamericana de Educación, v. 7, n. 2, 2016, p. 4-18.

Del sujeto y la repetición en la educación al reconocimiento ético como acto educativo. In: Araucaria. Revista Iberoamericana de Filosofía, Política y Humanidades, v. 19, n 38, 2017, p. 265-284.

Aprobación/desaprobación: dos caras de la razón evaluadora. Un debate filosófico y algunas claves de resistencia. Voces de la educación, v. 3, n. 6, 2018, p. 85-92.

Entonces, ¿qué es un dispositivo? De la matriz colonial de poder a los dispositivos (pedagógicos) contemporáneos. In: Voces de la Educación, v. 4, n. 8, 2019, p. 28-68.

Razón evaluadora/razón punitiva: relaciones y complicidades (o dos caras de la colonialidad pedagógica). Revista humanidades, v. 10, n. 1, 2020, p. 1-22.

Ricoeur, P. Historia y verdad. Madrid: Encuentro, 1990 [1955].

. Sí mismo como otro. México D. F.: Siglo XXI, 1996 [1990].

Lo justo. Madrid: Caparrós, 1999 [1995].

2006 [2004].

Caminos del reconocimiento. Tres estudios. México: Fondo de Cultura Económica, [2001].

Lo justo 2. Estudios, lecturas y ejercicios de ética aplicada. Madrid: Trotta, 2008

Educación y política. De la historia personal a la comunión de libertades. Buenos Aires: Prometeo/Universidad Católica Argentina, 2009.

Roca, D. Obra reunida III: estética y crítica. Córdoba: Universidad Nacional de Córdoba, 2008.

\begin{tabular}{|l|c|c|c|c|}
\hline Q Povista Dialectus & Ano 9 & n. 19 & Agosto-Dezembro 2020 & p. 25 - 37 \\
\hline
\end{tabular}



2012.

Obra reunida IV: escritos políticos. Córdoba: Universidad Nacional de Córdoba, 